\title{
Neolithic pottery at Polgar-10 (Hungary): measuring the habitus
}

\author{
John Chapman \\ University of Durham, Department of Archaeology, Durham, UK \\ j.c.chapman@durham.ac.uk
}

\begin{abstract}
It is self-evidently true that ceramics form the largest component of the artefact assemblages of the Neolithic and Copper Age of Central and Eastern Europe, yet we are still poorly informed about the final stage of the life of most vessels - their ultimate disposal. In this paper, I wish to consider the ways in which pottery can be studied with respect to disposal and deposition. An assessment of ten different kinds of pottery analysis is made, using site single contexts as the main unit of analysis. I propose that these analyses constitute ways of measuring Bourdieu's term "habitus". This contextual analysis is based on examples taken from the Neolithic settlement of Polgar-10, in North East Hungary, excavated by the Upper Tisza Project in 1994.
\end{abstract}

IZVLEČEK - Več kot očitno je, da med najdbami neolitika in bakrene dobe v Srednji in Vzhodni Evropi močno prevladuje keramika. Kljub temu še vedno malo vemo o končnih stopnjah življenja večine posod - ko so jih dokončno zavrgli. V članku obravnavam načine, kako lahko preučujemo keramiko glede na te končne stopnje (odlaganje in deponiranje). Ocenim deset različnih vrst analiz keramike in kot merilo analiz uporabim kontekst enega najdišča. Predlagam, da bi bile te analize podlaga za merjenje Bourdieujevega izraza "habitus". Vsebinske analize temelijo na primerih iz neolitske naselbine Polgar-10 na severovzhodnem Madžarskem, ki so ga izkopali leta 1994 v okviru projekta Zgornja Tisa.

KEY WORDS - Neolithic; Hungary; ceramic analyses; disposal; deposition

\section{INTRODUCTION}

Two of the characteristics of Neolithic and Copper Age archaeology in Central \& Eastern Europe are the predominance of settlement sites and the often extraordinarily large and diverse artefact assemblages generated by the excavation of these sites. These two characteristics have often been noted and usually been taken for granted apart from acting as good reasons for excavating these rich sites. But the presence of so many settlements and such masses of finds on them is not at all typical of Eurasian prehistory as a whole and raises the question of why this should have been so.

One way to approach this question is to consider the nature of the material remains which archaeologists study. Barrett $(1988 ; 1994)$ has proposed that archaeological evidence comprises the surviving fragments of those recursive media through which the practices of social discourse were constructed. Hence, the aim of archaeological investigation is the identification of the social practices, which led to the deposition of particular material residues in specific places. What is the effect of this re-focussing of research aims upon the way that archaeologists classify material residues? I suggest that the results are twofold: the consideration of closer links between humans, things and places, and a more active role for material culture in social practices.

The classificatory schemes developed for types of "refuse" by Schiffer $(1975 ; 1987)$ and Needham and Spence (1997) are permeated with one of the key foundation-myths of archaeology - the notion that archaeology is the science of rubbish or, as Julian 
Thomas (1991.56) put it, 'archaeology is concerned with the rubbish of past generations'. The designation of archaeology's principal object of study as 'rubbish' is remarkably widespread and has ramifications which stretch into all areas of the discipline. Different cultural values are expressed by the term 'rubbish' in various modern states but there are two aspects of the term which are widespread and which perhaps best characterise the cultural value of the term. First, rubbish designates something, which was once active, once in use, and now is passive, of no more use. Continuation of the past use may be prevented by breakage, circumscribed by replacement or the 'active' part of the material used up, leaving the 'passive' part for disposal. Secondly, because of this first aspect of value, rubbish is a material category, which should be separated from the processes of living. Ideas of pollution, whether expressed in terms of danger to health or well-being or aesthetic dis-pleasure, lie at the heart of this second aspect of the values expressed by rubbish. Thus, archaeologists carry a set of ideological assumptions about what they take to be rubbish today and it is not hard to see that they apply these modern ideological assumptions to the past.

There are two potentially serious problems with the application of modern ideological assumptions about rubbish to the prehistoric past. The first is that these assumptions widen the 'gulf' between the dead refuse of archaeological sites and the active social life whose practices contributed to the deposition of material culture, making it harder to theorise the connections between 'dead' rubbish and 'once-living' people. Thus it is not difficult to identify archaeological traditions in which description, classification and seriation of finds is the principal, if not the only, research goal. It is my contention that it is easier for researchers working in these traditions to continue this research by continuing to assume a large gap between rubbish and people. By contrast, objects produced and utilised within the household are part of that household not only during the 'life-spans' of those objects but also when they have been deposited.

The second problem is that it drastically narrows the interpretative possibilities for understanding the contexts and meanings of the deposition of our common resource - past material culture. If most of our finds are simply 'rubbish', we can hardly be expected to come to any sophisticated conclusions about the behaviour of the people who threw them away, nor can that behaviour be deemed to be anything but unproblematic.
I believe that there are grounds for demonstrating that one of the core assumptions of our discipline is false. I maintain that archaeology is not about rubbish as much as about deposition, generally of the structured variety. Thomas also maintains that the two modern ideological assumptions about the value of rubbish are also inappropriate for a study of prehistoric artefacts. Not only have many objects been deposited according to cultural rules underpinning categorical distinctions concerning disorder and order, purity and pollution, but also many of them have been broken deliberately before deposition. This applies not only to pottery, which fragments relatively easily, but also to a wide range of other, rarer objects such as altar-lamps, figurines and miniature furniture. It applies not only to items made of fired clay but also those manufactured out of harder materials such as bone, antler and even stone and metal. In short, object fragmentation is as fundamental to the Balkan Neolithic and Copper Age as is structured deposition (Chapman 2000).

If structured deposition of often deliberately broken objects is to be considered as a potential alternative to refuse disposal in the Balkan Neolithic and Copper Age, it is important to define the contexts in which such deposition takes place. In previous papers, I have considered three classes of site context found in Balkan NCA sites: above-ground features, such as roundels; cultural levels; and below-ground features, such as pits, shafts and wells (Chapman 2000a; $2000 b$ ). Three general points emerged from these reviews of depositional practices:

(1) The concentration of discarded material close to the home marks an important principle of dwelling in both tells and flat sites - a basic practice of settled life in which the identity of people, the things and the place are mutually reinforcing and reproduced in constant relation to the ancestors.

(2) Far from being nothing but a neutral means of disposing of unwanted 'refuse', digging pits, wells and shafts can be seen as an exchange with the ancestors - of new material for old - when the features are dug into earlier 'cultural layers'. This notion of digging into the past is especially germane to tell settlements, which are based upon the principle of living where one's ancestors have lived.

(3) The rejection of the $20^{\text {th }}$ century notion of refuse, with its twin correlates of the uselessness of 'dead' artefacts compared to 'functioning' living humans 
and the spatial separation of polluted artefacts from active, living humans, opens up a wide range of possibilities for the re-interpretation of the principal forms of deposit on settlement sites. The main impact is to raise the analytical potential for the identification of the active use of cultural material in everyday social practices and ritual occasions.

In my recent research on deposition in Central and Eastern Europe, I have focussed on special examples of deposition from a range of different sites and monuments. In this paper, I wish to narrow the scope of the investigation to a single site, at the same time seeking to explore more deeply the contextual links between pottery deposition and intra-site spatial variability.

The notion of habitus (Bourdieu 1977) refers to habitual behaviour, which has an unspoken basis of embodied tradition. Since sherd deposition near or in settlement features was a basic aspect of the Neolithic habitus in this region, my expectation is that many of the contexts will show signs of specific structuring in material deposition. In the first group of analyses, concerned with the ceramics themselves, I make use of the statistical concept of the "site norm" - often a calculation based upon the total pottery sample from Polgar-10 (e.g., the sherd size profile from all measured sherds). The "site norm" may be used as the standard against which to compare and contrast individual contexts. In this way, the site norm is the product of a range of different depositio-

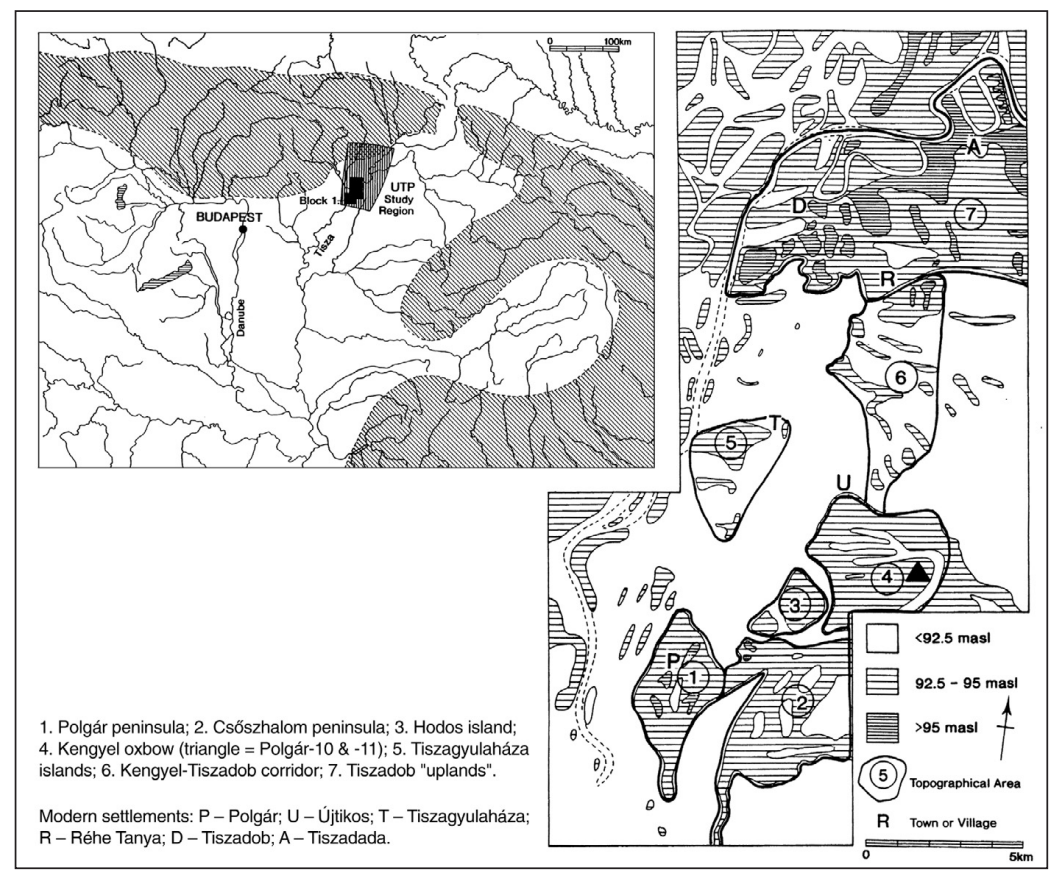

Fig. 1. Location map of Polgar-10. nal practices which, when found frequently enough, may be taken to represent the habitus in a general sense. Variations from the site norm will be considered not as exceptions to the habitus but rather as pointers to specific cultural preferences which would probably indicate some kind of structured practice.

\section{THE NEOLITHIC SITE OF POLGAR-10}

Fieldwork and subsequent excavation at Polgar-10 arose out of a motorway rescue programme led by Dr. Pal Raczky, on behalf of the Eotvos Lorand University Institute of Archaeological Sciences and the Deri Muzeum Debrecen. The Hungarian side fieldwalked the line of the motorway in 1993 and invited the Upper Tisza Project to excavate Polgar10 in September 1994. Polgar-10 proved to be an extremely rich example of a Neolithic site with the likelihood of one major, and several minor, flood episodes, sandwiched between Middle Neolithic deposits (Chapman 1995; Chapman et al. 1995) (Fig. 1). A sampling strategy was evolved which enabled the hand excavation of a reasonable number of contexts from each of the five occupation phases. Dry sieving and froth flotation of soil samples from each context provided the basis for the recovery of small ecofacts and objects. The excavation of the threatened part of the site was completed by the end of September 1994, prior to the planned start of motorway construction. The excavation report (Chapman et al., in prep.) attempts to interpret each individual context and then use the results in a series of three combinations - Phases, Zones and Context Types, to understand the processes of discard and deposition.

The site area threatened by the motorway was divided into three unequal sectors: the Central sector, the small Northern sector and the much larger Southern sector (Fig. 2). These sectors acted as a loose framework for the stratification of the sampling. The results of the first two test pits showed that there were two major stratigraphic units on the Central sector - a light grey silty soil, overlying a much darker blocky clay, which in turn overlay the dirty loess earlier identified at Polgar-11. Further investigation 
of the light grey silty sediment led to the hypothesis that it was a flood loam laid down in a single episode or a series of short-lived floods. The "flood deposit" was found in all of the test pits and, subsequently, in all of the excavation boxes. Ranging in depth between $0.25 \mathrm{~m}$ and $0.35 \mathrm{~m}$, it marked a convenient division of the deposits into three units: pre- flood, flood and post-flood. The pre-flood dark soil was identified as what is discussed above as a "cultural layer". Without careful excavation, it was impossible to predict how many occupation horizons were contained within the pre-flood "cultural layer". The postflood deposits were generally quite thin (maximum depth $-0.10 \mathrm{~m}$ ). Thus, a framework for sampling the site deposits was constructed at an early stage (Fig. 3).

The extra boxes in the Central sector were designed to give a wide spatial exposure to the post-flood features, as well as to test the homogeneity of the "flood deposit". They revealed a major "natural" feature which was presumably of significance to the early inhabitants - a channel running East - West through the site. The soil fill of this feature indicated that a low probability of running water moving through the channel, so the site stream became the site "boggy hollow". Much of the boggy hollow was filled in with "flood deposit".

As time moved on, it was clearly important to sample parts of the site outside the relatively small Central sector. Auguring and test pits in both the North and the South sectors enabled the validation of the overall sequence of sediments. Time constraints forced some serious decisions: the machining-off of the "flood deposit" and the pre-flood cultural layer in the North sector, in order to identify early features cut into the loess. The "flood deposit" was also removed by machine in the South sector but the cultu-

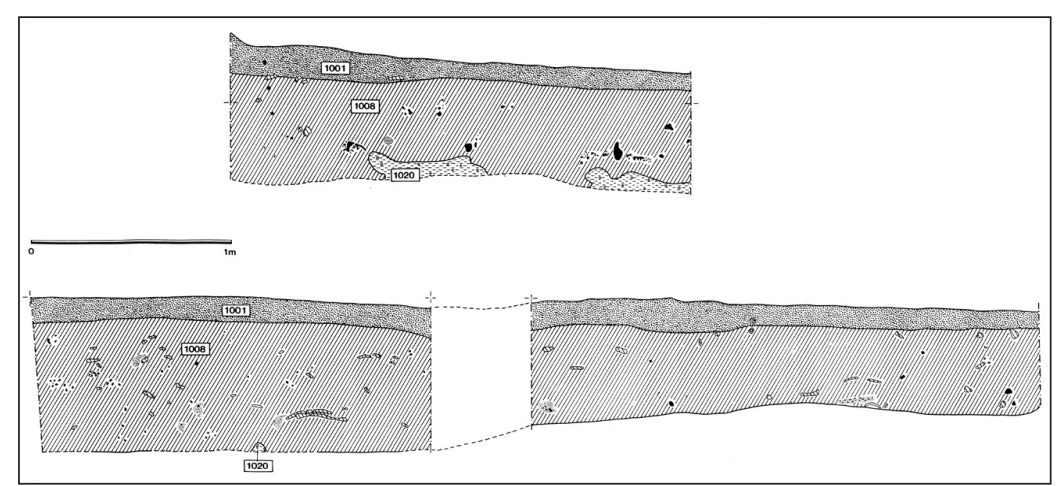

Fig. 3. North Sections, Trench AJ19B and AJ19C. ral layer was left for excavation of selected features - many of which showed up immediately after the removal of the "flood deposit". After excavation of the most striking features in the South sector, further limited removal of sediment by machine revealed further features cut into the dirty loess; this enabled the recovery of a reasonable number of contexts from the earliest part of the site occupation. In summary, the sampling strategy enabled excavation of a range of different contexts from each of the five Phases and from all of the three Zones.

The stratigraphic sequence at Polgar-10 consists of four cycles of fills and cuts. The sequence begins with the deposition of sterile, yellow aeolian loess at some stage of the Late Pleistocene. At the top of the yellow loess is a 10-15 cm thick deposit termed "dirty loess" - a lighter aeolian loess mixed with organic staining, flecks of charcoal and occasional Neolithic pottery. Whether this stratum represents the disturbance of the uppermost loess horizon by the earliest Neolithic occupation or a phase of early middle Holocene pedogenesis, which incorporated early, but scanty artefact deposition is not yet clear.

\section{Phase 1}

The first phase of cuts into the aeolian loess is composed of a series of archaeological features cut into and through the surface of the "dirty" loess. All of these features contained Middle Neolithic pottery in the Szatmar II style.

\section{Phase 2}

The second phase of fills concerns the gradual accumulation of what is termed in Hungarian archaeology a "cultural layer" or "occupation horizon" - viz., an organic-rich layer containing often high densities of ceramics 


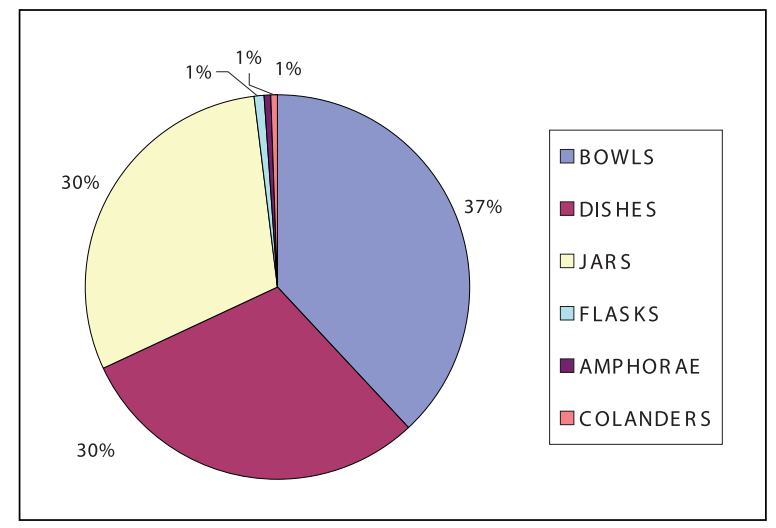

Fig. 4. Frequency of Shape types, total sample, Polgar-10.

and animal bones. The explanation for such accumulations is not entirely clear; at Polgar-10, the introduction of material through flooding and the inwashing of clay from wattle-and-daub constructions outside the excavated area are two plausible means by which $15-30 \mathrm{~cm}$ of deposit built up within the Middle Neolithic period. Admixture of materials discarded or deposited by people on their living surface with the flood deposits and the house remains probably accounts for the density of finds in this horizon.

\section{Phase 3}

The second phase of cuts is represented by the cutting of archaeological features into the top of the "cultural layer". Their finds comprise no pottery but Middle Neolithic material.

\section{Phase 4}

The third suite of fill comprises the inwashed material from one single large, or a series of smaller, flood episodes. The occurrence of features lying on an active surface within the flood loam makes the latter explanation seem more probable. A certain amount of ceramics was incorporated into the flood loam, suggesting that active living surfaces were close at hand. Since no material later than the Middle Neolithic was found in the flood loam, it may be concluded that we have represented here a set of Neolithic floods.

\section{Phase 5}

The third phase of cut features is represented by a group of features cut into the uppermost surface of the flood loam. While a relatively small quantity of pottery, and even fewer animal bones, were preserved in these features, no material datable to a period later than the Middle Neolithic has been recovered.
The fourth and final cycle of fills and cuts can be dated to the post-Neolithic period. The infilled materials consist of post-Neolithic flood loams and erosion deposits, which accumulated over the longue duree and apparently undisturbed by later prehistoric and historic occupation.

A series of five AMS radiocarbon dates places the Neolithic deposits firmly in the late sixth - early fifth Millennia CAL BC (Tab. 1) (p.c., T. Higham).

In terms of the context types at Polgar-10, the basic contrast has already been made between fills and cuts. However, four more specific Context Types have been defined, leaving a fifth category for "Other" types: cultural layers, fill deposits, flood deposits and pits.

The contexts defined as "cultural layers" have in common a fairly high to high organic content and a moderate to high density of artefacts. Fourteen such features are identified at Polgar-10, all in Phase 2. These units are highly variable in terms of size and range and quantity of finds.

Fill deposits are found in every Phase except Phase 4 - defined as a special kind of fill - flood deposits. Their defining trait lies in the negative nature of their deposition - they do not have a high organic content nor high densities of finds, nor are they features cut into another matrix. Fourteen such contexts make up this potentially disparate Context Type, whose range and quantity of artefacts is just as variable as in the cultural layers.

The six examples of flood deposits are, by definition, restricted to Phase 4. The diversity and quantity of finds in some of these contexts indicates that often surprisingly large quantities of material have been washed into these deposits.

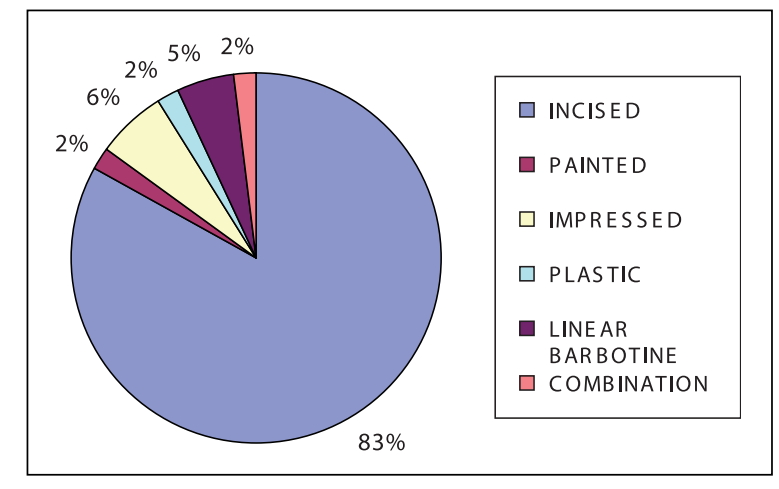

Fig. 5. Frequency of Decorative techniques, total sample, Polgar-10. 
John Chapman

The fourth specific Context Type comprises Pits. The size of these features has been recorded in such a way that it is possible to assess the density of finds in a quantitative way. In two cases, the pits are just large enough to hold a single vessel (the so-called pot-pits); otherwise the pits can range up to $8.2 \mathrm{~m}^{3}$ in volume. The finds density can range from no finds at all

\begin{tabular}{|lcccc|}
\hline Lab No. & Phase & Date & $\begin{array}{c}\text { Calib Date } \\
\text { Range (2 } \sigma)\end{array}$ & $\begin{array}{c}\text { Associated } \\
\text { Pottery }\end{array}$ \\
\hline OxA-9633 & I & $6440+/-60$ BP & $5480-5320$ & Szatmar II \\
\hline OxA-9634 & I & $6365+/-50$ BP & $5475-5255$ & Szatmar II \\
\hline OxA-9635 & I & $6245+/-45$ BP & $5310-5190$ & Szatmar II \\
\hline OxA-9675 & II & $6190+/-90$ BP & $5325-4900$ & Tiszadob \\
\hline OxA-9637 & IV & $6290+/-45$ BP & $5365-5205$ & Late Tiszadob \\
\hline
\end{tabular}

Tab. 1. A series of five AMS radiocarbon dates.
The final Context Type is the most variable, including as it does a few examples of a diverse range of contexts with little to unite them. The most numerous examples include burials and pottery and/or daub concentrations but occasional examples of burnt floors and a single hearth complete the group.

In summary, Polgar-10 is a multi-phase Neolithic settlement with a medium-sized ceramic assemblage recorded in single contexts, each located within one of three zones. Total occupation is likely to be discontinuous, spanning several hundred years.

\section{OUTLINE CHARACTERISTICS OF THE CERAMIC ASSEMBLAGE}

The Neolithic pottery deposited at Polgar-10 constitutes an assemblage of cca. 25000 sherds, including over 2700 rims and over 3300 decorated sherds. Initial categorisation of rims and decorated sherds was completed by Rhodri Jones and Jerome Edwards as their dissertation topics at the University of Newcastle upon Tyne (Jones 1996; Edwards 1996); since then, further studies have been made by the author.

The basic characteristics of the assemblage are an overall domination of coarse wares over fine wares (a ratio of 3:2). A total of seven fabrics have been

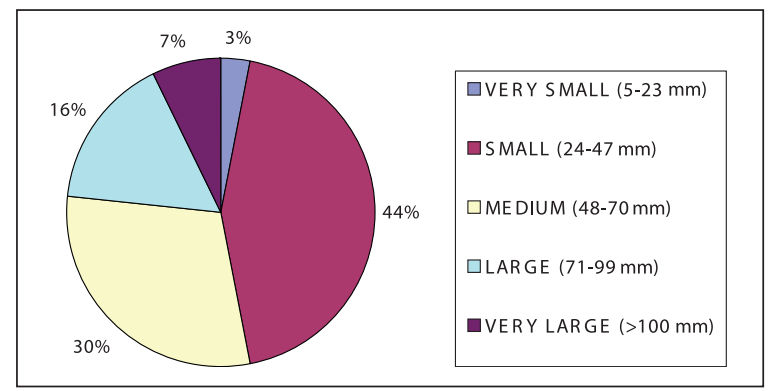

Fig. 6. Frequency of Size categories of total sample of Polgar-10 sherds. defined: four for the coarse wares and three for the fine wares (Tab. 2).

The assemblage comprises six overall shape types: three common types - bowls (38\%), dishes (30\%) and jars (31\%) - and three rare types - flasks (1\%), amphorae $(<1 \%)$ and colanders (<1\%)(Fig. 4). Decoration is dominated by the Incised technique (83\%), with minor contributions from five other techniques: Painted (2\%), Impressed (6\%), Plastic (2\%), Linear Barbotine (5\%) and a combination of these techniques (2\%) (Fig. 5). The Incised decorative motifs have been sub-divided into five motif groups: wavy lines $(5 \%)$, curvilinear (10\%), rectilinear ( $42 \%)$, deep, simple incision (8\%) and a combination of these motifs (18\%). Such summary statistics provide basic yardsticks against which to measure single-context difference - as we shall see, an important tool for the assessment of various modes of discard.

It is not the aim of the paper to present a Phase-byPhase account of the history of settlement at Polgar10. Rather, I shall seek to discuss examples of context types in terms of the ceramic evidence.

\section{CERAMIC ANALYSES: SEARCHING FOR STRUC- TURE IN THE DISCARD DATA}

We are now in a position to explore some individual contexts from Polgar-10 to assess their ceramic contents against the mode(s) of deposition used. Ten types of analysis have been performed on the Polgar-10 contexts and their ceramic inventories. The first five analyses focus on the characteristics of the ceramics themselves: (1) a fragmentation analysis of sherd size, following Buko; (2) an erosion analysis of the sherds, following Buko; (3) an analysis of the vessel parts represented; (4) an analysis of the fabrics of the context group; (5) an analysis of the decorational intensity. The next five analyses are devoted to spatial - contextual aspects of deposition: (6) the location of whole vessels in specific locations; (7) the concentration of sherds in a small 

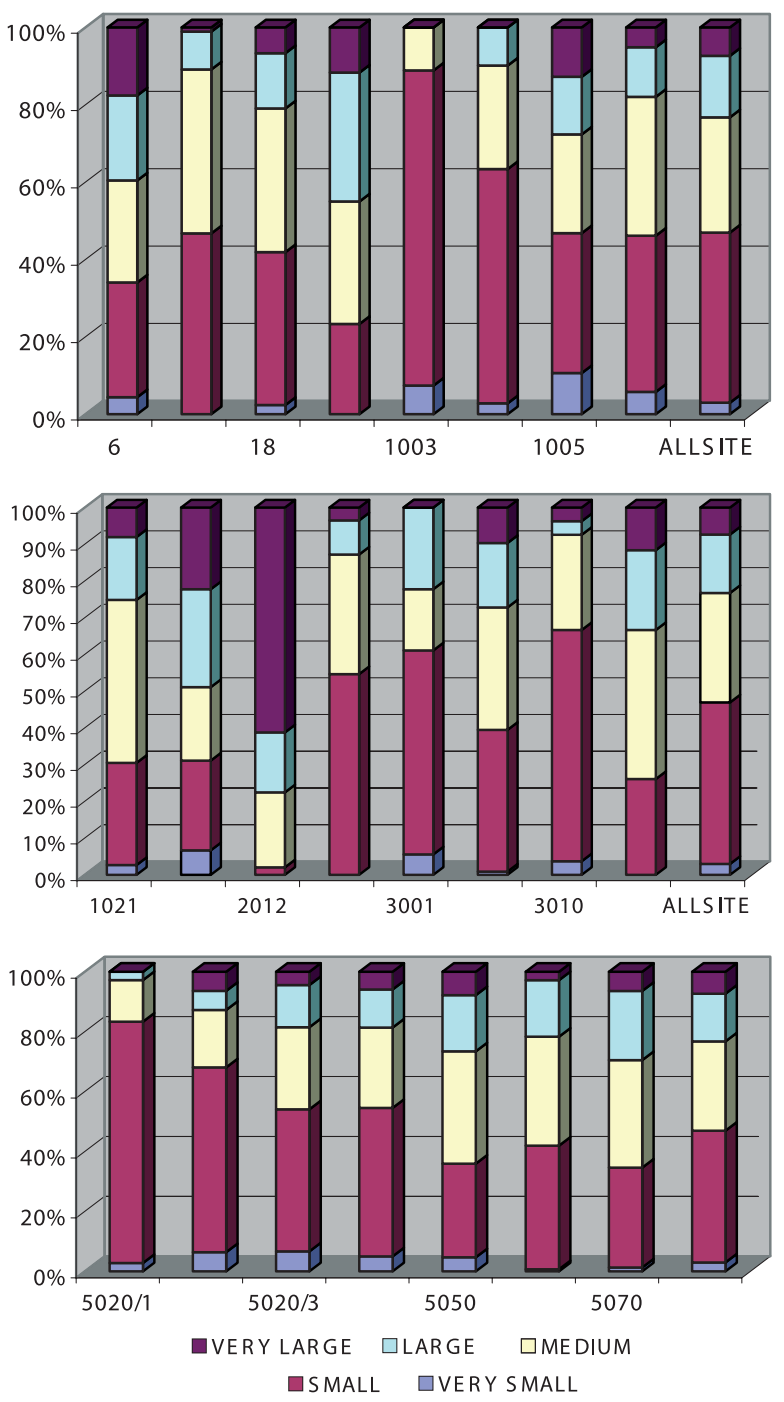

Fig. 7. Sherd size profiles by context, Polgar-10.

area; (8) the concentration of sherds in a specific phase of a context's "life-history"; (9) the association of pottery with other classes of finds deposited in a structured way; and (10) the juxtaposition of differing finds densities in adjacent contexts. Clearly, the multiple occurrence of ceramic characteristics supportive of an interpretation of structured deposition for the same context would strengthen such an interpretation.

\section{Sherd size}

The notion that sherd size is an important primary characteristic of a ceramic assemblage has been recognised for some time, particularly in the work of the Polish Medieval potter specialist, Andrzej Buko. Buko (1987; 1990) has devised a range of indices for the measurement of Medieval pottery (see below, pp. 134-136, for erosion), which allow him to compare and contrast individual contexts or context groups according to the values of these indices. An example is the way in which Buko has demonstrated that the ceramics in the fill of the first and second fortification ditches in the Medieval town of Sandomierz were derived from different places because of their differing size characteristics (Buko 1987).

This approach was followed for the Polgar-10 pottery, with one major difference. The specific technique used to measure Medieval vessel size was the number of vessel parts included in the sherds (e.g., Buko 1987.Fig. 5). Since the profiles of the majority of Neolithic vessels are not so highly developed, a simple size measurement was preferred - viz. the largest measurement across the surface of the sherd. Plotting these measurements on a histogram indicated several size peaks, which enabled the identification of five size categories on the basis of the interquartile ranges of the sherd sizes in each category: Very Small, Small, Medium, Large and Very Large (Fig. 6) (cf. Buko 1990.Ryc. 2). The only problematic aspect of this technique was discovered empirically: the inclusion of only two or three very large sherds in a sample of $20-30$ sherds led to a distortion of the results. Removal of these sherds from the analysis led to a second set of results, which could be compared to the first - and often produced a more satisfactory result.

A total of 2262 sherds in 21 separate contexts was analysed for sherd size by Mr David Brookshaw in the 1999 laboratory season in Budapest. The sample derived from 11 pits, 2 "fill" contexts, 2 flood contexts, 3 cultural layers and 3 Other. The overall picture shows a strong predominance of Small sherds (44\%), followed by Medium sherds (30\%) (Fig. 7). In those contexts with such high frequencies of Small and Medium sherds, it may be suggested that the processes of deposition were characteristic for the site

\begin{tabular}{|ll|}
\hline \begin{tabular}{ll} 
Coarse Ware Fabrics \\
\hline 1 & large, thick-walled, very coarse and large grit temper \\
\hline 2 & medium wall thickness, gritty surface, mineral temper \\
\hline 3 & thin - medium-thick walled, coarse surface with some \\
signs of smoothing
\end{tabular} \\
\hline 4 & fairly thin-walled, gritty surface, mineral temper \\
\hline Fine Ware Fabrics \\
\hline 5 & medium-thick walled, burnished inside and out \\
\hline 6 & thick-walled but burnished surface \\
\hline 7 & thin-walled, highly burnished surface \\
\hline
\end{tabular}

Tab. 2. Fabric types for the total assemblage, Polgar-10. 


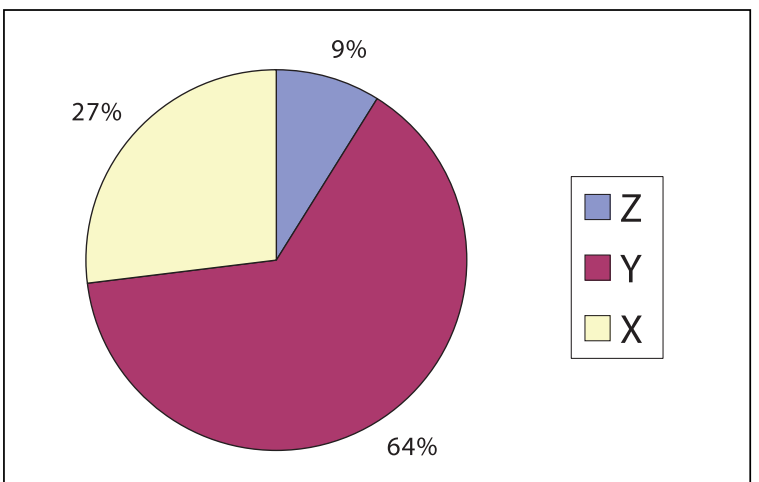

Fig. 8. Frequency of Erosion categories of total sample of Polgar-10 sherds.

habitus, in that the overall sum of factors contributing to such a sherd size profile was typical for moderate rates of pottery fragmentation and a reasonably small distance over which the sherds may well have moved. Any context in which the sherd size profile deviates markedly from this site norm may well indicate the operation of different discard processes.

The majority of contexts $(n=13)$ show sherd size profiles broadly comparable to that of the site norm. However, there is a strong emphasis on Very Large sherds in three contexts:

- 0006 sherd concentration on the surface of a shallow pit

- 2001 surface pottery and daub concentration

- 2012 pot-pit, with many large sherds belonging to a single vessel

It would indeed be extraordinary if the proportion of Very Large sherds was not exceptionally high in the case of the pot-pit 2012. However, the two other contexts stand out through the sherd size range from other similar surface concentrations.

There are a further five contexts which differ from the site norm through the extremely high frequency of Small sherds:

- 1003 shallow scoop with much pottery in a small feature

- 1004 long, narrow, flat-bottomed pit

- 3010 sandy fill into which material appears to have been washed

- 5020/1 clayey fill cut into the loess

- 5020/2 lowest part of the cultural layer

In the cases of 3010 , the high fragmentation rate appears to be linked to inwash of material culture from adjacent deposits during a flood. However, a plausible alternative explanation for the high fragmenta- tion of the other four contexts is deliberate smashing of pottery into small pieces ("Scherbenmachen" pace Makkay 1983). The high densities of pottery in 1003 are another feature worth noting in the context of structured deposition. It should, however, be noted that three of these contexts have small sample sizes of fewer than 40 sherds $(1003,3010$ and 5020/1).

In summary, one aspect of pottery fragmentation of widespread applicability in contextual studies is the sherd size profile. While there may well be general expectations of such profiles, in practice such expectations should be calibrated against each site's fragmentation data, in order to identify a well-founded norm. The second stage is the identification and explanation of cases diverging from that norm. At Polgar-10, high frequencies of Very Large sherds occur in three contexts - one with strong circumstantial evidence for structured deposition of a single pot in a pit, while five contexts are dominated even more than usual by Small sherds - perhaps in some cases an indication of deliberate pottery-smashing.

\section{Sherd Erosion}

The study of the erosion of sherd fractures is a second field of research highly developed by Andrzej Buko (1987; 1990). Buko has defined four typical stages of erosion on Medieval glazed sherds, rang-
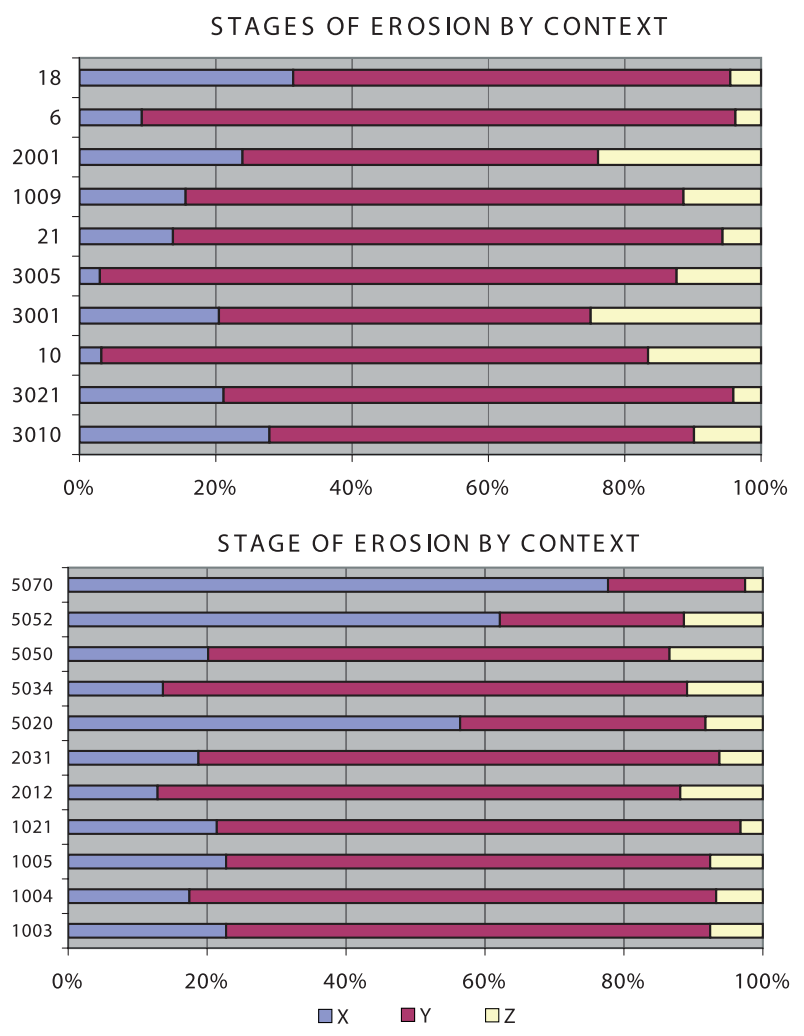

Fig. 9. Sherd erosion profiles by context, Polgar-10. 


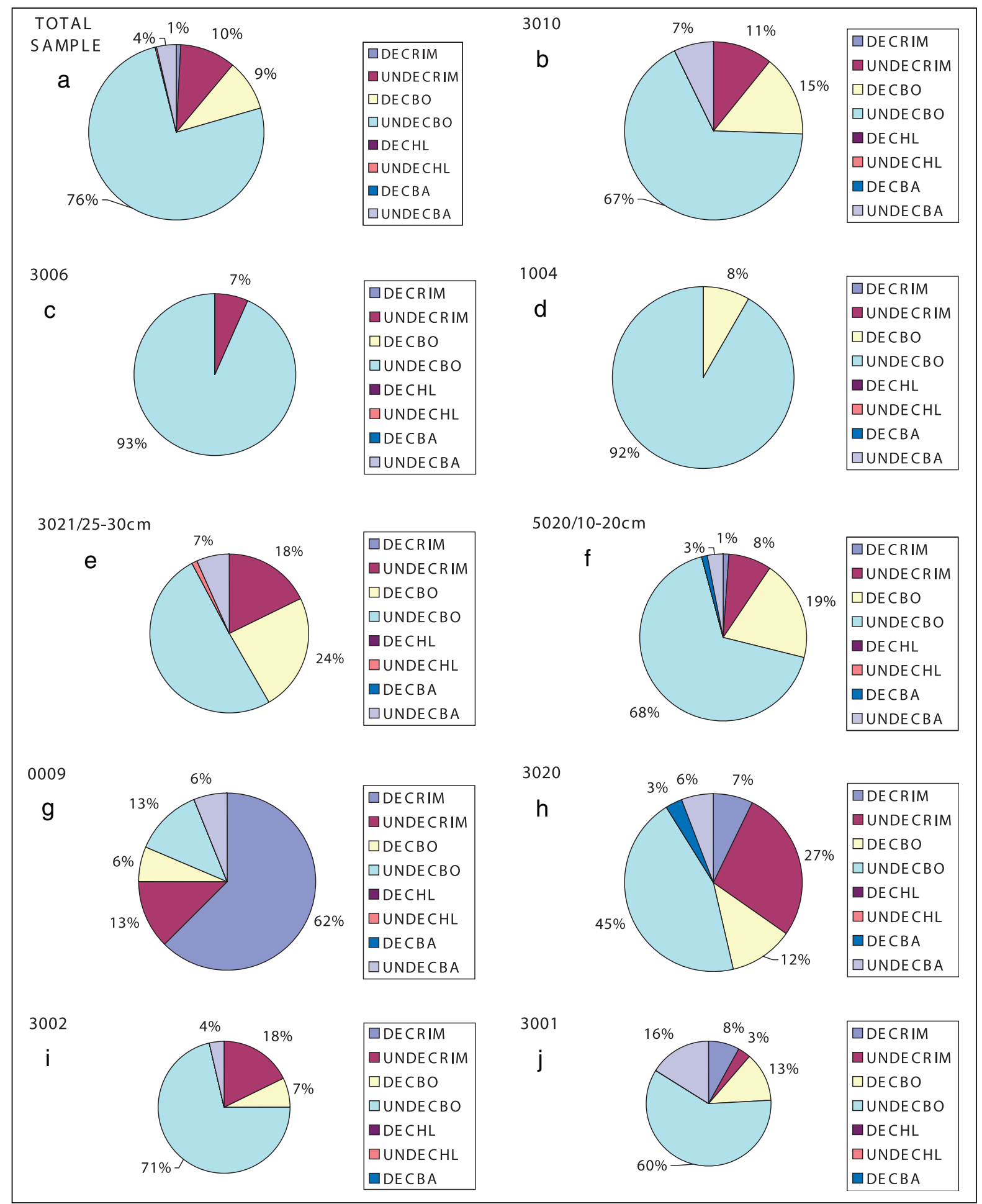

Fig. 10. Potpart distribution by context, Polgar-10.

ing from uneroded sherds with glaze intact or locally worn to sherds with well-rounded sherds with the original shape uncertain (Buko 1990.Ryc. 1). As with sherd size, Buko (1990) uses sherd erosion profiles to define deposition patterns at the site of Storvagan, in the Lofoten Islands. The Basic logic is the more eroded the sherd, the longer it has been on an active living surface, with abrasion and comminu- tion from the elements and cumulative damage from other cultural practices. Conversely, the more rapidly the sherd is incorporated into a context of preservation, such as a pit, the less likely the sherd would suffer high-level erosion.

In the case of the Polgar-10 sample, three erosion stages were defined by Mr David Brookshaw in his 
1999 analysis, in which Buko's "uneroded" stage 0 was omitted as not relevant: Stage X: sherd has sharp, well-defined edges; Stage Y: sherd is becoming rounded, with local wear on body surface; and Stage Z: well-rounded sherds with the original shape uncertain. There were no major technical problems with the application of the method to the sample sherds, which amounted to 2111, again discovered in 21 contexts.

The overall site picture shows a strong preponderance of medium-level sherd erosion (64\%), with rather more low-level than high-level sherd erosion (Fig. 8). This would suggest that, at the most general level, the pottery assemblage at Polgar-10 was not exposed greatly to either natural or cultural elements of transformation but that, for the most part, sherds were incorporated reasonably quickly into sub-surface features or buried on once-active surfaces.

The key question is the degree of fit of sherd erosion profiles from individual contexts to the site norm. The context-based erosion profiles are presented by context type (Fig. 9). There is a much higher proportion of contexts with variance from the site norm with the erosional data than with the pottery fragmentation information. Three pit contexts (5020, 5052 and 5070) share a far high percentage of lowlevel erosion than is the norm, ranging from $60-$ $80 \%$. This would suggest that the ceramics in these pits were incorporated rather faster than usual - an interpretation consistent with structured deposition. The opposite case - a higher-than-usual incidence of high-level erosion - is also attested in two contexts:

- 2001 surface pot and daub concentration

- 3001 cultural layer

The suggestion here is that these sherds had been on the active living surface of the settlement for a re-

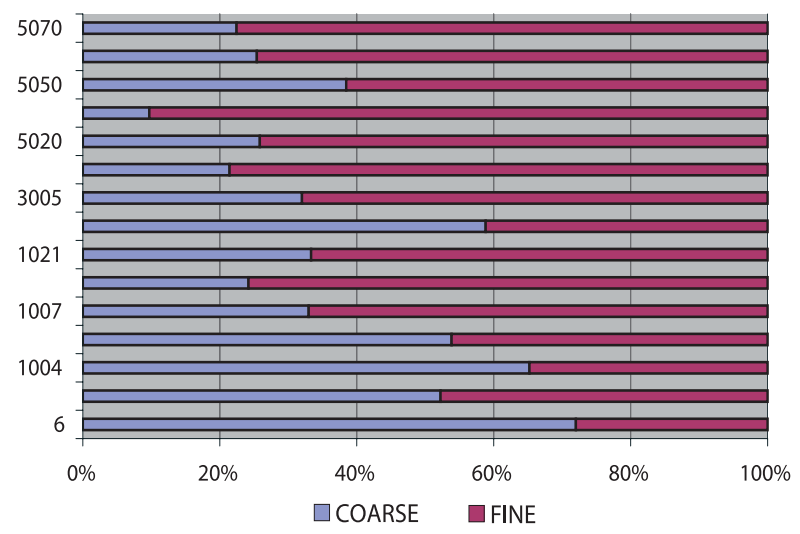

Fig. 11. Fabric distribution of rim sherds by context, Polgar-10. latively long time before they were discarded into their respective contexts. The third and final variance is quite common, occurring in nine contexts - five pits (1004, 1021, 2012, 2031 and 5034), two cultural layers (0010 and 3005), one flood deposit (0006) and a surface sherd concentration (0021). These contexts share a higher-than-average frequency of medium-level erosion, varying from $77 \%-87 \%$ and marking an extreme dominance of the norm. The common occurrence of such sherd erosion profiles does not necessarily mean that the possibility of structured deposition is excluded from these contexts, since pottery fragmentation and deposition would seem to be part of the settlement's habitus. Yet it is in the distinctive erosion profiles that a sense of structuring is more readily grasped.

In summary, the sherd erosion profiles of a sizeable sample of Polgar-10 contexts show a strong emphasis on medium-level erosion, suggesting that material culture remained on the living surface for a reasonable amount of time before final deposition. However, a small number of contexts indicate much more rapid deposition and a slightly larger group suggests long exposure to natural and cultural processes of transformation.

\section{Potpart analysis}

The analysis of Pot Parts is based on the number of vessel parts found in each context, in comparison with the standard site norm of all the potparts. Each sherds has been classified by vessel part in eight standard categories: decorated and undecorated variants on rims, body sherds, handles/lugs and bases. For the purpose of this analysis, the very small number of unidentifiable sherds has been omitted.

The results of the analysis are presented as a series of pie-charts of sherd counts; sherd weight statistics are omitted here for the sake of brevity (Fig. 10). The site norm indicates that, as with most site assemblages, the most frequent element is the Undecorated Body sherd (overall - $76 \%$ by number), with similar frequencies of Undecorated Rims and Decorated Body sherds (Fig. 10a). Base sherds and Decorated Rims are rare, while handles and lugs fall below $1 \%$ of the sample. A total of 52 contexts or sub-contexts (mostly layers in a pit) contained sherd samples large enough for analysis. All but eight of the 52 contexts were dominated by Undecorated Body sherds (e.g., 3010: Fig. 10b). The eight contexts will be briefly discussed to examine the claim 


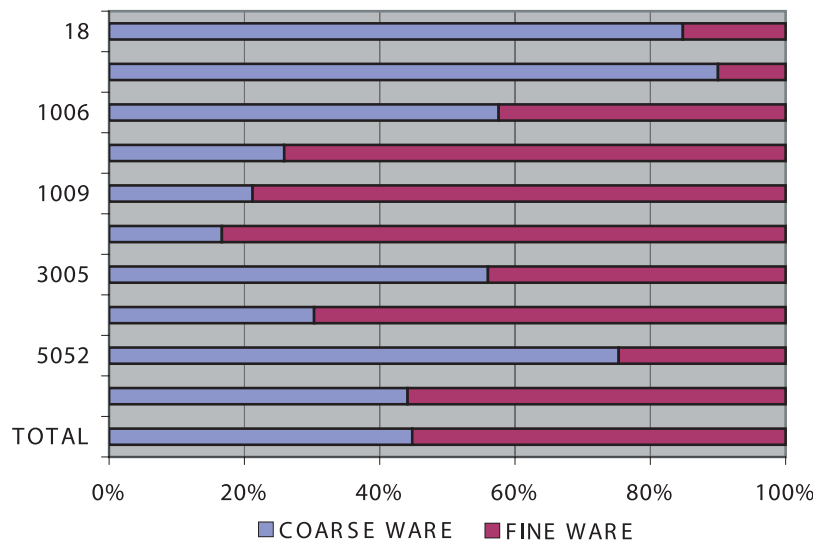

Fig. 12. Fabric distribution of decorated sherds by context, Polgar-10.

of structured deposition. Although three of the eight unusual contexts have small sample sizes $(<30$ sherds), their potpart profiles remain interesting examples of unusual deposition.

Some contexts stand out for their absence of specific potparts. The part of the cultural layer excavated as Context $3006(n=61)$ was remarkable for its total absence of decorated sherds (Fig. 10c); a similar case occurs in the small sample $(\mathrm{n}=14)$ from the adjacent Context 3007 - the only two site contexts without decorated sherds. A related profile comes from Context $1004(\mathrm{n}=24)$, the only site context containing nothing but Body sherds, for the most part undecorated (Fig. 10d). While the 1004 sample is small, the unusual potpart profile raises questions of deliberate cultural selection.

By contrast, other contexts have unusually high rates of feature sherd deposition. Context 3021 - part of the fill of the boggy hollow in the centre of the excavated area - is typical of all boggy hollow fill deposits in its higher-than-average proportion of feature sherds (over $40 \%$ in sub-context $25-30 \mathrm{~cm}$ : Fig. $10 \mathrm{e}$ ). This suggests that the boggy hollow is a special place for artifact deposition, marked by positive selection of decorated and other feature sherds. A similar selection occurs in Context 5020, part of the cultural layer in the Southern Zone, where Decorated Body sherds receive preferential deposition (Fig. 10f). The context with the lowest proportion of Undecorated Body sherds on site is the fill Context 0009 (Fig. 10g), with one such sherd in a small assemblage of 16 sherds. In comparison to $5-25 \%$ on most other contexts, the percentage of Rim sherds $70 \%$ or 11 sherds - indicates strong selection, a view supported by the fact that most of the rim sherds derive from at least three, and possibly as many as five, different vessels. A similar preference in a much lar- ger assemblage derives from the flood deposit Context $3020(\mathrm{n}=432)$, with very high ratios of rims (34\%) and Decorated Body sherds (12\%) (Fig. 10h). Equally, the small sample from the cultural layer Context $3002(\mathrm{n}=24)$ favours Undecorated Rims (18\% or 4 sherds deriving from at least three vessels) (Fig. 10i). The final unusual context - the cultural layer 3001 - indicates a strong selection of Base sherds (11 examples, or 16\% rather than the normal 1\%) (Fig. 10j).

The general background point relating to the interpretation of the potpart data concerns vessel fragmentation (Chapman 2000), where a mass of data is presented on deliberate breakage of vessels and the deposition of the resulting fragments in graves and pits. Additional data supports the absence of large parts of those vessels represented by rim sherds at sites such as Nea Nikomedeia (Pyke \& Yiouni 1996) and Wyszogrod (Kobylinski \& Moszczinski 1992). Thus, one of the most important questions for a study of fragmentation, viz., "where are the missing parts ?", applies with equal force to the potpart profiles for any settlement context. This is a large question and we cannot expect the emergence of a satisfactory answer from the Polgar-10 data. However, even in this small-scale investigation, two cases have been recognised of preferential deposition of rims from several vessels, with one or maximum two rim sherds per vessel (Contexts 0009 and 3020). A further example concerns the pot-pit Context 2021, where nothing but the rim sherds from two or three vessels were found together with most of a storage-jar placed in the pit. A parallel case concerns the eleven Base sherds from Context 3001, representing five or six vessels with fewer than a handful of non-Base sherds found in that area. Equally, the higher-than-usual deposition of feature sherds in the boggy hollow is a sign of the structuring of material discard.

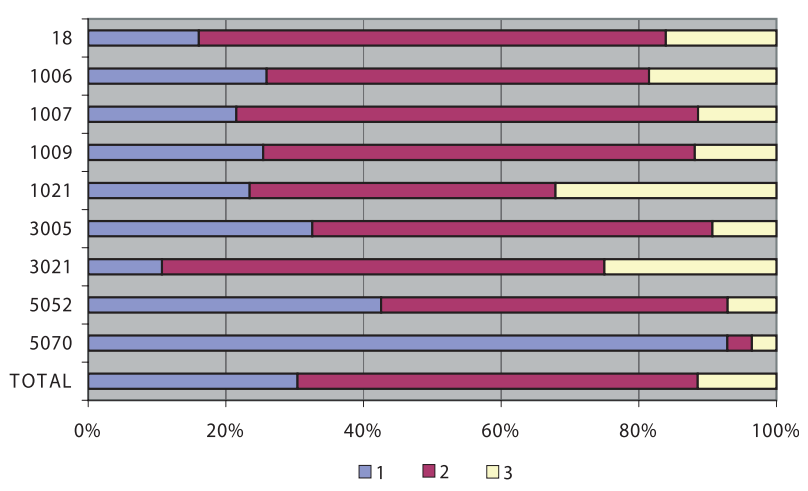

Fig. 13. Distribution of decorational intensity by context, Polgar-10. 


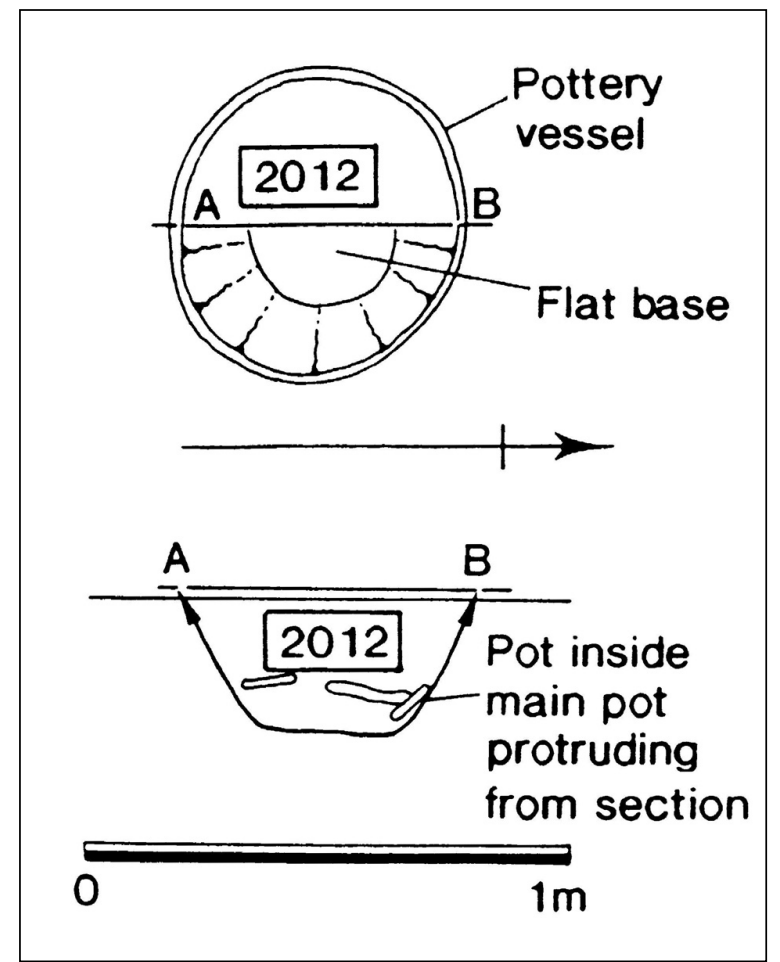

Fig. 14. Plan and section of pot-pit, Context 2012.

The principle of pars pro toto may be invoked here, with sherds symbolising the complete vessel and all that the vessel itself stands for in the network of social relations mediated by material culture. The absence of so much pottery from any given vessel is taken as a sign that deliberate fragmentation often preceded selection of cultural material for deposition. Potpart analysis does not yet confirm that structured deposition occurs in every context with normal selection of ceramic elements but the small number of exceptional contexts would appear to mark the strong preference for certain types of material culture consonant with structured deposition.

\section{Fabric analysis}

It has already been stated (p. 132, Tab. 2) that seven fabric categories have been identified for the rim sherds in the Polgar-10 assemblage. However, these fabric categories are too detailed for an analysis of fabric variability by context, which is, in any case, possible for only 15 contexts for rim sherds and 10 context for decorated sherds. The fabric analysis is therefore based upon the most general distinction between fine wares and coarse wares. Once again, the underlying principle is that the site norm is a representation of the habitus for the cultural material deposited at Polgar-10 and that variations from that norm presuppose deliberate cultural selection. The site total of decorated and/or rim sherds comprises
2412 sherds, of which $59 \%$ are fine ware sherds. In comparison with the rim sherds, $64 \%$ of which are fine wares, there is a smaller percentage of fine ware sherds amongst the decorated wares (56\%).

The breakdown of rim sherds into fine and coarse fabrics is presented below (Fig. 11). There is a level of fine wares substantially higher than that of the site norm in six contexts, ranging from $74 \%$ to $92 \%$. The small pit Context 5034 contains such a high percentage of fine ware rims that deliberate selection of this cultural material is highly probable. Equally, coarse ware rims occur much more frequently than normally in five contexts, including the shallow pit Context 0006 , with $60 \%$ coarse wares. This suggests that the concept of "site norm" is not particularly useful here and that, instead, there is a bimodal distribution of contexts where either coarse or fine ware rim sherds are favoured.

In the case of decorated sherd fabrics (Fig. 12), only one context has a fabric distribution similar to that of what may be, in this case inaccurately, termed the "site norm". The decorated ware fabric profiles resemble not so much a site norm as a bimodal distribution of contexts: high concentrations of fine wares (70-83\%), contrasted with contexts with high concentrations of coarse wares (57-91\%). The surface sherd concentration Context 0021 has the highest proportion of coarse ware, at $91 \%$.

What is intriguing is that fabric peaks for rims do not match those for decorated sherds in four cases (Contexts 1007, 1021, 3005 and 5070), although only one context with a high fine ware rim count is also characterised by a high coarse ware decorated sherd count (pit 5052). These mismatches support the notion of specific choices of fabrics whereby cultural messages are mediated by ceramic deposition.

In summary, the fabric choices in specific contexts present an exception to the previously robust concept of the site norm, with bimodal preferences for coarse and fine wares in different contexts. The selection of high frequencies of either fabric suggest something more structured in depositional practices.

\section{Decorational complexity analysis}

The analysis of decorational complexity seeks to measure the quantity of decoration on the surface of a pot. The analysis is a response to the proposition that the Alfold Linear Pottery group is characterised by an increase in decorational complexity through 
time (Tringham 1971.128-133). The initial data for the analysis was gathered by Jerome Edwards (1996. 26-27, 38 \& Fig. 12).

Three classes of decorational complexity have been defined by Edwards: Intensity Level 1: very low-level density; Intensity Level 2: medium-level density; and Intensity Level 3: high-level density. The total sample of decorated sherds ( $\mathrm{n}=1128$ sherds) shows a preponderance of medium-level decoration (58\%), with rather more than double low-level than highlevel intensity (Fig. 13). Although the results will not be presented in detail here, it should be noted that Tringham's proposition is confirmed. This means that any variations in this diachronic trend will affect individual contextual variability.

Nonetheless, at a very general level, it is possible to conclude that a higher proportion of sherds with medium-level intensity was deposited in the boggy hollow than elsewhere on site, although that was not the case with high-level intensity sherds. In the case of individual contexts, the pattern is one of considerable variability, with low-level intensity varying between $10 \%$ and $95 \%$, medium-level intensity varying between $5 \%$ and $75 \%$ and high-level decorational intensity varying between $5 \%$ and $30 \%$. The highest incidence of high-level intensity, well above the site norm, is found in the boggy hollow fill (Context 3021) and in the small pit 1021, while the greatest concentration of low-level intensity, again well above the site norm, is found in the Phase 1 pits 5052 and 5070.

In summary, at first sight, the diachronic trend in increasing decorational intensity would appear to make problematic any interpretation of structured

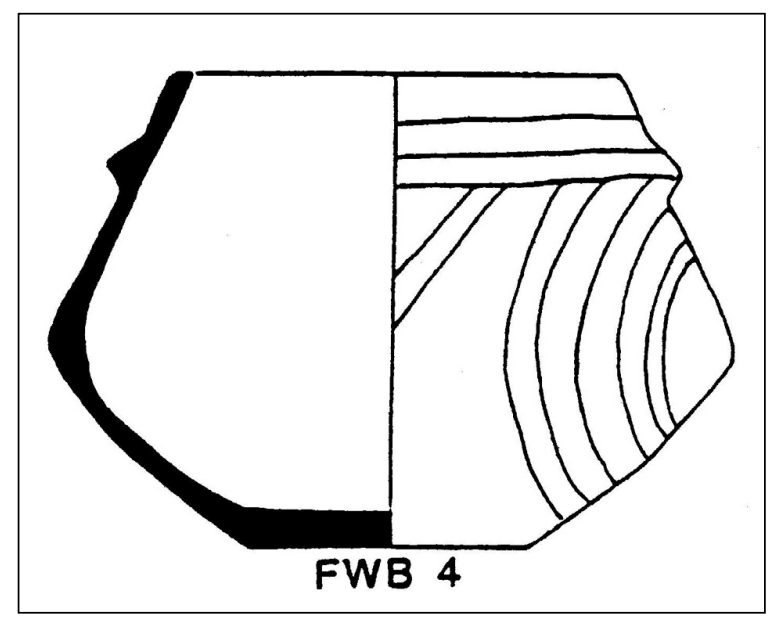

Fig. 15. Carinated bowl, placed at the base of pit Context 5021. deposition from these data. However, the chronological trend is a post-hoc generalisation made by archaeologists, which does not explain the quotidian practices resulting in such varied deposition. What it suggested is that the selection of low-level decoration in the early occupation at Polgar-10 was abandoned at a later date, with the development of a different set of cultural preferences. These changing preferences are best seen in those few contexts in which there are strong selections of either high- or low-intensity decorational intensity.

I now turn to the spatial and contextual aspect of the analyses, which rely not so much on statistical exploration of the habitus but a contextual discussion of the finds.

\section{Deposition of whole vessels}

The discovery of complete vessels in the excavated part of Polgar-10 is such a rarity that their occurrence is a sign of structured deposition. Two such vessels merit attention: the storage-jar placed in the pot-pit 2012 and the carinated dish placed in the bottom of the pit 5021 .

A small pit, measuring $0.6 \mathrm{~m}$ in diameter and $0.4 \mathrm{~m}$ in depth, containing the lower part of a single vessel, with sherds from other vessels placed inside the main pot (Fig. 14). The pit has been cut into the upper surface of the flood loam and filled with the vessel. The upper part of the vessel would originally have projected above the land surface by as much as perhaps $50 \mathrm{~cm}$. The large orange coarse ware Straight-Sided Jar was filled with large sherds coming from other vessels, indicating the deposition of fragmentary, partial remains of several other pots, perhaps as many as five.

Context 5021 was an irregular oval pit, containing fill varying from black to dark brown, similar to the cultural layer, measuring $1.9 \mathrm{~m}$ in length by $2 \mathrm{~m}$ in depth by $0.5 \mathrm{~m}$ in depth; the finds in the fill form a group of mostly undiagnostic sherds. However, on the base of the pit was placed a small carinated bowl with incised decoration (Fig. 15). This vessel, with a highly burnished surface and medium-level decorational intensity, appears to have been a foundation deposit to define the deepest deposit of the pit.

There can be little doubt that these two vessels are exceptional both in their completeness and in their contexts of deposition. They can thus be interpreted as instances of structured deposition. 


\section{Horizontal sherd concentrations}

One of the most characteristic forms of deposition at Polgar-10 is the surface concentration of sherds and/ or daub. Four examples are discussed here as typical of the class of finds.

Context 0021 was a surface spread of sherds and other material, $1.2 \mathrm{~m}$ in length and $1 \mathrm{~m}$ in width, resting on and slightly cut into the flood loam material of Context 0018. The context comprises the deposition of a large quantity of varied ceramics, with little else except for animal bones, where high meat values predominate for the pig bones. The relatively high values for Large and Medium sherds suggest deliberate deposition on the surface of the flood loam, an interpretation not contradicted by the erosion data. The main characteristics of the pottery are the high values for coarse wares and the variety of decorative motifs in a reasonably small sample.

Context 1003 was a shallow scoop, incompletely excavated, in the North East part of the trench AJ14P, at least $1.5 \mathrm{~m}$ in length and $1 \mathrm{~m}$ in width and $0.07 \mathrm{~m}$ in depth. The fill consisted of fine grey sandy loess, probably re-deposited. The large quantity of finds, especially pottery, for such a small feature suggests deliberate deposition or in-washing of the finds from a surface in close proximity to the pit.

Context 2001 comprised a surface concentration of pottery and daub, measuring $5 \mathrm{~m}$ in length, $3.5 \mathrm{~m}$ in width and $0.1 \mathrm{~m}$ in depth. The main feature was a deliberate deposit of a fairly large quantity of ceramics and daub, with a more varied size profile than usual and a very small proportion of feature sherds. The narrow range of finds classes suggests a specialised deposit, incorporating sherds which are more eroded than usual.

Context 3008 was a small, shallow pit, with an ashy fill derived from a hearth, measuring $0.8 \mathrm{~m}$ in length by $0.8 \mathrm{~m}$ in width by $0.05 \mathrm{~m}$ in depth, which may have been truncated through machine excavation of the upper part of Context 3001/3004.. There is a high rate of discard, especially ceramic, for such a small pit, including a very high proportion of decorated sherds. The lack of identifiable animal bones and the absence of lithic remains suggests a rather specialised deposit, as does the incorporation of two of the largest daub fragments found on site.

These contexts share the high density of pottery and/ or daub in a confined space, with additional criteria which lend support to the idea of deliberate deposition.

\section{Vertical sherd concentrations}

There is strong evidence for the structured deposition of material culture at the beginning of a sequence of deposition (e.g., the base of a pit) and/or as the closing deposit (e.g., the very latest deposit in a pit fill) (Chapman 2000a). There are only a few examples of this class of deposit at Polgar-10. One example has already been mentioned - the placing of a whole carinated bowl in the very bottom of pit 5021 (see above, p. 139 and Fig. 15). Two further deposits consist of fills designed to close pits.

Part of Context 0006 comprises a concentration of potsherds in the upper fill of a shallow pit, some $2.2 \mathrm{~m}$ in length, $1.1 \mathrm{~m}$ in width and $0.15 \mathrm{~m}$ deep. No or very few finds at the base of the pit, in primary fill; almost all finds occur on the ground surface of the flood loam, indicating deposition at the very end of the life of this pit. Erosion is hardly likely to have occurred through significant movement of the finds into the area of the pit. Thus, the finds represent the remains of in situ deposition of not only pottery but also a large quantity of daub, suggesting the proximity of a structure. The sherd fragmentation data supports this interpretation, with the relatively high incidence of Very Large and Large sherds. The strong emphasis on coarse wares with low-intensity decoration, in a wide variety of pot parts, suggests that the majority of vessels were not for public display or consumption. Yet the large number of shape subtypes for a relatively small sample of rim sherds (1 new sub-type per every two rim sherds) suggests a large number of vessels was deposited here.

Part of Context 0007 consists of a concentration of potsherds at the very top of a small, shallow pit, 0.6 x $0.6 \times 0.25 \mathrm{~m}$ in size. The pit has been truncated and contains mostly sherds from the same vessel. Although the pit was large enough for a single coarse ware vessel, this was not a pot-pit as seen elsewhere on site but, rather, many sherds from one vessel were deposited in the uppermost part of pit fill, which had itself been previously truncated, perhaps also related to site flooding. Many more sherds were also deposited, perhaps at the same time as the sherds from the same vessel, and this spread extended over a wider area than just the pit zone. When encountered at other Neolithic sites, such as Opovo, in the Vojvodina (Russell 1994), such examples of vertical sherd concentrations have been in- 
terpreted as the material remains of periodic rituals, possibly seasonal, which mark the beginning or the completion of the cycle of pit digging and filling.

\section{Association of pottery with other finds in struc- tured deposits}

Since the vast majority of contexts with evidence for structured deposition at Polgar-10 involve ceramics, there are few remaining contexts to discuss.

One such is Context 1009 - a concentration of animal bones, pottery and shell, deposited on the North side of Context 1008, near the base of the fill of the boggy hollow" and directly above the carbonate loess. The concentration measures $1.5 \mathrm{~m}$ in length, $0.75 \mathrm{~m}$ in width and $0.15 \mathrm{~m}$ in depth. The most concentrated zone for the deposition of animal bones in the excavated part of the site, with a large number of sherds, mostly small- and medium-sized Fine wares with incised decoration, indicating the likelihood of deliberate placement of these bones, some of which were still articulated. The strong emphasis on medium-level erosion indicates that few of these sherds had been transported over a long distance, into a secondary position. The absence of lithic remains suggests that this area was specifically devoted to the disposal of bones and sherds, although the occurrence of large daub fragments suggests the presence of a structure in the vicinity.

It may be suggested that the social practice of deposition of animal bones and shells in the boggy hollow also included the placing of ceramic fragments so as to associate the different classes of material culture.

\section{Juxtaposition of contrasting finds}

There is a wide range of sites in the Balkan Neolithic and Copper Age with well-documented examples of the use of binary oppositions to make statements about human categorisation processes (Chapman 2000a). These contexts may involve one of several contrasts: nature: culture, upper fill: lower fill; or left side of pit: right side of pit. Another practice involves cyclical or repeated deposits of two different classes of material: at one of the Early Neolithic shafts at Endrod 119, dark black organic matter and pure yellow loess (Makkay 1992; Chapman 2000a).

There is only one such example excavated so far at Polgar-10: the shallow pit Context 3009, whose ashy fill, derived from a (nearby) hearth, measures $3 \mathrm{~m}$ in length by $1 \mathrm{~m}$ in width by $0.05 \mathrm{~m}$ in depth. In contrast to the ash-filled pit Context 3008 with a proliferation of finds (see above, p. 140), there were no finds in this pit. The juxtaposition of two small ash-filled pits - one with a high density of finds and one with no finds at all - would appear to represent an example of binary categorisation, in which different individuals or groups are associated with the multiplicity - or absence - of material culture.

\section{DISCUSSION AND CONCLUSIONS}

This article has sought to demonstrate the potential of a wide range of methodologies for the investigation of structured deposition on Neolithic settlements. The discussion will be focussed around two questions: (1) how well do these methodologies work? and (2) how can the deposits at Polgar-10 be interpreted in the light of these methods?

The methods presented and used in this study are of potentially widespread applicability for anyone who seeks to study Neolithic ceramics in these ways. The most important aspect of all the ten methods discussed here is that they require little additional data collection to the normal recording of any advanced ceramic analyst. The author has found no technical problems with any of the methods; the analyses relating to the ceramics presuppose categorisations, which could, in theory, be developed empirically for each site. My general conclusion is that any ambiguities remain at the interpretative level.

The first question concerns the statistical gloss on the concept of habitus - an analytical device which may not meet with Bourdieu's approval. The general issue is whether or not we are entitled to infer traditional practice from a suite of activities, which have repetitive material consequences which are measurable and quantifiable. The difficulty here is that the activities leading to material deposition may be so varied that it would be unconvincing to include all practices within the term "habitus". Nonetheless, it can be maintained that practices such as pottery firing and burnishing to create such and such a range of fabrics would be considered as part of the core of cultural traditions - and therefore central to the habitus - by students of material culture as well as ethnographers; hence, the archaeological remains do result from the core activities in the $h a-$ bitus. If the practice of deliberate fragmentation can also be demonstrated as a practice central to the $h a$ bitus of the Neolithic and Copper Age of Central and 


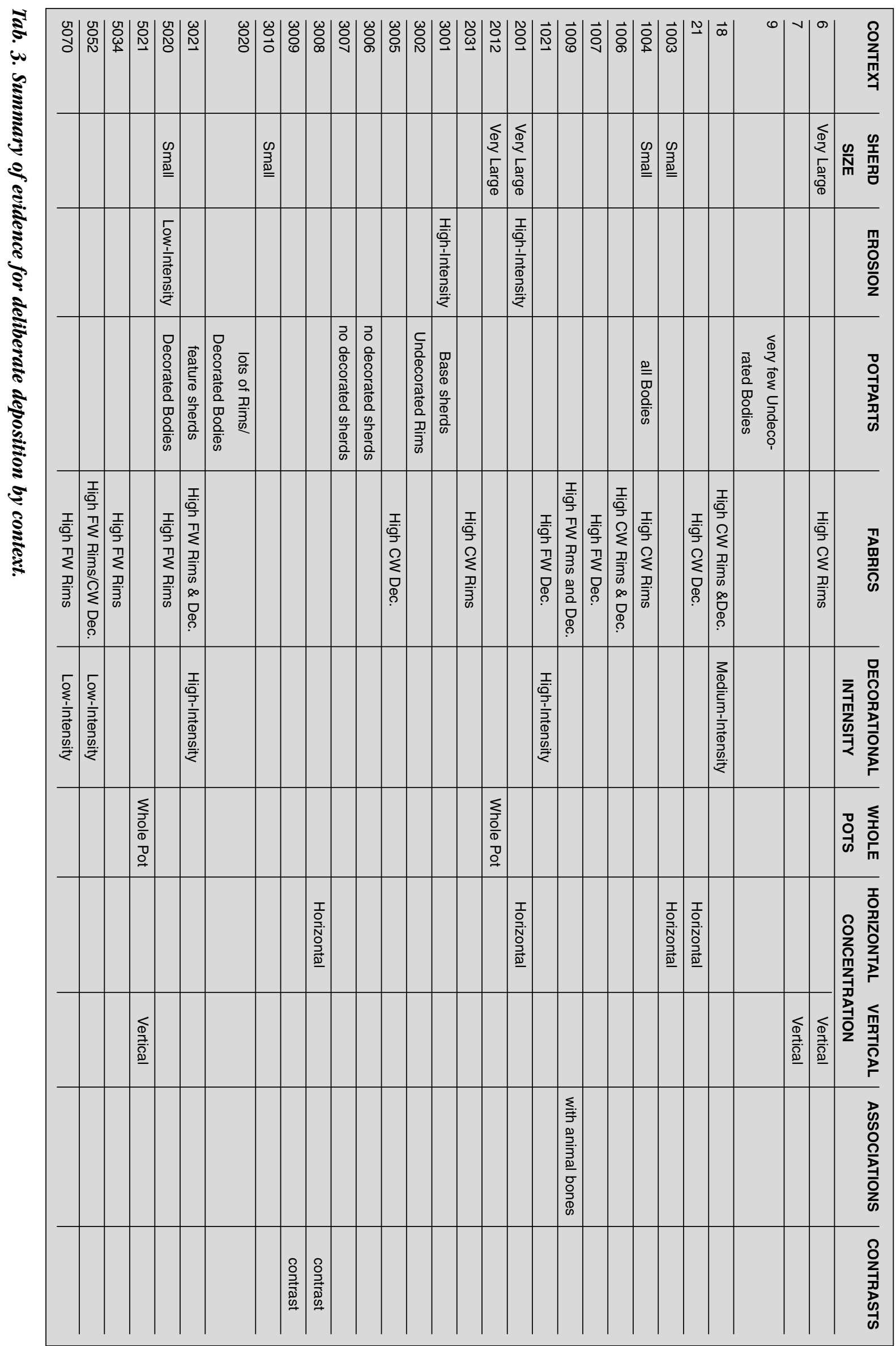


Eastern Europe, then many of the analyses relating to fragment size and erosional conditions may also represent ways of measuring the habitus. It will also be maintained that the spatial practices which charactise deposition at Polgar-10 are also part of the habitus of the community, indeed related to the wider cultural traditions of Alföld Linear Pottery dwelling. If the technological and depositional practices typical of Polgar-10 are accepted as portraying the habitus of that community, then the methods used here to analyse the variability of such practices are, pari passu, a preliminary and probably oversimplified way of measuring the habitus.

I have mentioned already that each of these methods carries with it an interpretative ambiguity; perhaps this is inevitable with prehistoric cases. An example concerns the sherd size analysis. The variable of sherd size is dependent upon many aspects of material practice, from the size of the vessel to the way it is stored/kept and any post-use practices. There will be some uncertainty over an interpretation of deliberate deposition of sherds whose size varies widely from the site norm. But if a context with such a sherd size profile shows other indications of structured deposition, the sherd size profile may well be used as supporting evidence. In terms of interpretational ambiguity, the most problematic single measure would appear to be the decorational intensity analysis, which apparently has to cope with diachronic changes in intensity. However, these chronological changes are themselves caused by variations in the habitus which deserve an explanation - i.e., rather more than an assertion that such decorational changes occur because of the passage of time.

I present a summary of the indices of potential structured deposition (Tab. 3). This summary demonstrates three points: (1) almost $40 \%$ of all of the excavation contexts at Polgar-10 show some signs of evidence for deliberate deposition (29/73); (2) half of the these contexts show two or more signs of deliberate deposition in their ceramic finds (14/29), with one context (5020) showing as many as four converging lines of evidence; and (3) two-thirds of the contexts show evidence relating to ceramic aspects of deliberate deposition only (19/29), with only six contexts with evidence from both ceramic and spatial analyses. These summary statistics demonstrate that there is potentially quite a wide occurrence of deliberate deposition on this settlement and that many of the contexts have converging lines of mutuallysupportive evidence. It will be left to the reader to decide whether or not these figures support the no- tion that deposition of material culture is part of the broader framework of the habitus. But I wish to propose that the contextual evidence from this settlement lends some support to this case.

ACKNOWLEDGEMENTS
I am grateful to Dr. Miha Budja for the invitation to
the Neolithic Seminar in Ljubljana in November 2001
and for the offer of a place in this periodical for the
ensuing paper. I wish to thank the British Academy,
National Geographic, The Society of Antiquaries of
London, the Prehistoric Society, the Universities of
Durham and Newcastle upon Tyne and the Hunga-
rian Academy of Sciences for the funding which ena-
bled the Polgar-10 rescue excavation to take place. I
am grateful to the Hungarian National Archaeologi-
cal Committee and the Deri Muzeum, Debrecen, for
the permit to carry out the work. Dr. Pal Raczky and
his Polgar team were helpful in organising many as-
pects of our work and I am grateful to him and to the
Mayor of Polgar, Mr. Jozsef Olah, for their constant
support. But most of all, I am grateful to the digging
team, including students from Hungary, Britain and
Italy for their hard work in a very busy month, and
to Dave Brookshaw, who completed the fragmenta-
tion analysis and erosion analysis for the Polgar-10
sherds in summer 1999.




\section{REFERENCES}

BARRETT J. 1988. Fields of discourse: reconstituting a social archaeology. Critique of Anthropology 7/3: 5-16.

1994 Fragments from antiquity. Oxford, Blackwell.

BOURDIEU P. 1977. Outline of a theory of practice. Cambridge: Cambridge University Press.

BUKO A. 1987. L'utilisation de la poterie dans l'analyse des processus de stratification. In J. Chapelot, H. Glime and J. Pilet-Lemieres (eds.), Fabrication commercialisation - utilisation: 23-32.

1990. Wykorzystanie zjawiska erozji ceramiki w analyzach procesow formowania sie stanowisk osadniczych. Sprawozdania Archeologiczne XLII: 349-359.

CHAPMAN J. 1995. A Neolithic flood in Eastern Hungary. PAST (Summer 1995): 9-10.

2000 Fragmentation in archaeology. People, places and broken objects in the later prehistory of South East Europe. London: Routledge.

2000a Pit-digging and structured deposition in the Neolithic and Copper Age of Central and Eastern Europe. Proceedings of the Prehistoric Society 60: 61-87.

2000b 'Rubbish dumps' or places of deposition? Neolithic and Copper Age settlements in central and eastern Europe. In A. Ritchie (ed.), Neolithic Orkney in European perspective: 347-362.

CHAPMAN J., LASZLOVSZKY J. and SHIEL R. 1995. A Neolithic flood in eastern Hungary: the Upper Tisza Project 1994. Archaeological Reports for 1994 (Durham and Newcastle upon Tyne): 8-17.

CHAPMAN J., GILLINGS M. and SHIEL R. S. in prep. Lowland settlement in North East Hungary: excavations at the Neolithic site of Polgar-10.

EDWARDS J. 1996. An analysis of Neolithic pottery decoration from the 1994 excavation at Polgar, Hungary, considering variations in style through time and across context. Unpub. Undergraduate dissertation, University of Newcastle upon Tyne Dept. of Archaeology.
JONES R. 1996. An analysis of the form and function of a Neolithic pottery assemblage excavated in the Upper Tisza region of North East Hungary. Unpub. Undergraduate dissertation, University of Newcastle upon Tyne Dept. of Archaeology.

KOBYLINSKI Z. \& MOSZCZYNSKI W. A. 1992. Conjoinable sherds and stratification processes: an example from Wyszogrod, Poland. Archeologia Polona 30: 109-126.

MAKKAY J. 1983. Foundation sacrifices in Neolithic houses of the Carpathian Basin. In E. Anati (ed.), The intellectual expressions of prehistoric art and religion: 157-167.

1992. Excavations at the Koros culture settlement of Endrod-Oregszolos. In S. Bokonyi (ed.), Cultural and landscape changes in south east Hungary 1: Reports on the Gyomaendrod Project. Series Major 1 (119): 121-194.

NEEDHAM S. P. \& SPENCE T. 1997. Refuse and the formation of middens. Antiquity 71: 77-90.

PYKE G. \& YIOUNI P. 1996. Nea Nikomedeia I: the excavation of an Early Neolithic village in northern Greee 1961-1964. The excavation and the ceramic assemblage. Athens: British School at Athens.

RUSSELL N. 1994. Hunting, fishing and feasting: human uses of animals in Neolithic south east Europe. Ph.D. thesis, University of California at Berkeley.

SCHIFFER M. J. 1975 Behavioral archeology. London: Academic Press.

1987 Formation processes of the archaeological record. Albuquerque, NM: University of New Mexico Press.

THOMAS J. 1991. Rethinking the Neolithic. Cambridge: Cambridge University Press.

TRINGHAM R. 1971. Hunters, fishers and farmers of Eastern Europe, 6000-3000 BC. London: Hutchinson. 